\title{
Versatile Strategy for the Divergent Synthesis of Linear Oligosaccharide Domain Variants of Quillaja Saponin Vaccine Adjuvants
}

\author{
Alberto Fernández-Tejada ${ }^{\star}, \mathrm{a}$, Derek S. Tan ${ }^{\star}, \mathrm{a}, \mathrm{b}$, and David Y. Gin ${ }^{\mathrm{a}, \mathrm{b}, \sharp}$ \\ ${ }^{a}$ Chemical Biology Program, Memorial Sloan Kettering Cancer Center, 1275 York Avenue, New \\ York, NY 10065, United States \\ bTri-Institutional Research Program, Memorial Sloan Kettering Cancer Center, 1275 York \\ Avenue, New York, NY 10065, United States
}

\section{Abstract}

We describe a new, versatile synthetic approach to Quillaja saponin variants based on the natural product immunoadjuvant QS-21. This modular, divergent strategy provides efficient access to linear oligosaccharide domain variants with modified sugars and regiochemistries. This new synthetic approach opens the door to the rapid generation of diverse analogues to identify novel saponin adjuvants with improved synthetic accessibility.

\begin{abstract}
Adjuvants are critical components of modern subunit vaccines that induce enhanced immune responses to the coadministered antigens. ${ }^{1}$ The saponin natural product $\mathrm{QS}-21^{2}$ is a $\approx 2: 1$ mixture of apiose and xylose isomers at the terminal $\operatorname{sugar}^{3}$ of the linear oligosaccharide domain (Figure 1). Despite being one of the most potent ${ }^{4}$ and promising immunoadjuvants under clinical investigation, ${ }^{5}$ QS-21 has several liabilities including scarcity ${ }^{2}$ and heterogeneity ${ }^{6}$ from the natural source, chemical instability, ${ }^{7}$ dose-limiting toxicity, ${ }^{5 \mathrm{c}}$ and a poorly understood mechanism of action ${ }^{8}$ that has impeded the rational design of improved saponin adjuvants. To address these limitations, our group previously completed the total syntheses of QS-21-Api (1) and QS-21-Xyl (2), ${ }^{9}$ and developed a semisynthetic approach ${ }^{10}$ that enabled systematic investigation of structural variations in each of the four domains of QS-21. Introduction of amide linkages into and simplification of the acyl chain domain ${ }^{11}$ followed by extensive carbohydrate truncation ${ }^{12,13}$ provided chemically stable, simplified saponins incorporating a trisaccharide moiety in the linear oligosaccharide domain ${ }^{12}$ and lacking the entire branched trisaccharide, exemplified by lead compound $\mathbf{3}$ (SQS-1-0-5-18). ${ }^{13}$ While these previous studies yielded potent, less toxic saponin variants in sufficient quantities for preclinical evaluation, larger amounts will be needed for clinical research and, ultimately, large-scale deployment in vaccine formulations. Thus, a key remaining challenge is to identify new saponin variants that can be accessed via streamlined synthetic routes. This would be facilitated by the development of divergent synthetic
\end{abstract}

tand@mskcc.org; alberto.fernandezt@gmail.com..

¥Deceased March 22, 2011. 
approaches, in which a wide range of such scalable saponin variants can be generated rapidly.

Herein, we report a new series of linear oligosaccharide domain variants designed specifically for improved synthetic accessibility: two terminal disaccharide variants, a dirhamnose variant 4 (SQS-1-0-10-18) and a lactose variant 5 (SQS-1-0-11-18), the latter synthesized in only 16 total steps, and a 2-galactosamine variant 6 (SQS-1-0-12-18), which also features regiochemical modifications around the bridging monosaccharide. To access the latter two saponin variants efficiently, we developed a new, modular synthetic route involving initial attachment of the bridging monosaccharide residue to the triterpene core followed by installation of various terminal disaccharides. In contrast to our previous convergent approach, ${ }^{11-13}$ this new divergent route provides rapid access to diverse variants in the linear oligosaccharide domain of the Quillaja saponins.

Synthesis of our previously identified lead compound 3 required 23 total steps with 14 steps in the longest linear sequence (LLS). ${ }^{13,14}$ Notably, synthesis of the linear trisaccharide alone required 16 steps. Thus, we designed three new saponin variants with specific consideration to synthetic efficiency based on selection of readily-available carbohydrate building blocks. In dirhamnose variant $\mathbf{4}$, repetition of the rhamnose residue would allow increased synthetic convergence. In lactose variant $\mathbf{5}$, use of commercially available lactose as the terminal disaccharide would significantly reduce the overall step count. In the regioisomeric 2galactosamine variant $\mathbf{6}$, use of the readily available 2-azidogalactose residue would avoid the lengthy synthesis of the original 4-azidogalactose acceptor ( $c f .3$ ), while also changing the regiochemical relationship of the appended acyl chain domain and terminal disaccharide.

Dirhamnose variant 4, was prepared using our original convergent approach, via initial synthesis of the selectively protected linear trisaccharide $\mathbf{1 2}$ from previously described monosaccharide building blocks $\mathbf{7}, \mathbf{8}$, and $\mathbf{1 0}^{11,12}$ using stereoselective dehydrative glycosylation $\left(\mathrm{Ph}_{2} \mathrm{SO}, \mathrm{Tf}_{2} \mathrm{O}\right)$ reactions (Scheme 1) ${ }^{15}$ Notably, the rhamnosyl acceptor 8 was accessible in only two steps as an intermediate en route to rhamnosyl donor $\mathbf{7}$. Trichloroacetimidate donor $\mathbf{1 2}$ was then coupled with protected quillaic acid triterpene $\mathbf{1 3}$ ([PQA]-OH) ${ }^{1313}$ under Schmidt conditions to afford, after benzene-selenol reduction of the azide, ${ }^{16}$ the $\beta$-glycosyl ester 14 . The amine was treated with activated $N$-Boc-6aminohexanoic acid (15), then subjected to global deprotection via hydrogenolysis $\left(\mathrm{H}_{2}\right.$, $\mathrm{Pd} / \mathrm{C})$ and acid hydrolysis $\left(\mathrm{TFA} / \mathrm{H}_{2} \mathrm{O}\right)$ to provide the fully deprotected 6-aminocaproic amide 16. Late-stage installation of the aryl iodide by acylation with the $N$ hydroxysuccinimide (NHS) ester of 4-iodobenzoate $(\mathbf{1 7})^{13}$ gave dirhamnose variant 4 (SQS-1-0-10-18) in 22 total steps (14 steps LLS). ${ }^{14}$

Next, we pursued synthesis of lactose variant 5. In initial efforts using the original convergent approach, en bloc glycosylation of the triterpene C28-carboxylic acid with a number of pre-assembled lactosyl-4-azidogalactosyl donors was unsuccessful under both Schmidt (the trisaccharide trichloroacetimidate was unstable) and $\mathrm{Ph}_{2} \mathrm{SO} / \mathrm{Tf}_{2} \mathrm{O}$ dehydrative conditions (the glycosyl ester was formed with undesired a-selectivity). To overcome this problem, we envisioned that the trisaccharide could be installed in a modular fashion involving stepwise, $\beta$-selective monoglycosylation of the triterpene with a 4-azidogalactose 
residue and subsequent installation of the terminal disaccharide. This new approach would also provide more efficient, divergent access to analogues in the linear oligosaccharide domain than our original convergent strategy. Thus, Schmidt glycosylation of $\mathbf{1 3}$ with orthogonally protected imidate $\mathbf{1 8},{ }^{12}$ followed by careful deacetylation $(\mathrm{NaOMe}, \mathrm{MeOH})$ to avoid desilylation of the triterpene, gave the glycosyl ester 19 with complete $\beta$-selectivity due to anchimeric assistance by the $\mathrm{C} 2$-acetate neighboring group (Scheme 2). We noted that this selectively protected triterpene-azidogalactose alcohol $\mathbf{1 9}$ is a versatile intermediate for modular diversification with a variety of terminal disaccharides.

Initial attempts at glycosylation of triterpene-azidogalactose alcohol 19 with a commercially available peracetylated lactosyl bromide under Koenigs-Knorr conditions were unproductive, with significant orthoester formation due to the steric hindrance at the azidogalactose $\mathrm{C} 2$ position. However, the corresponding perbenzoylated lactosyl bromide 20, ${ }^{17}$ prepared conveniently and scalably in one step from commercially available lactose (cf. 7-step synthesis for original rhamnose-xylose disaccharide in $\mathbf{3}$ ), afforded the desired triterpene-trisaccharide in excellent yield using a modified Koenigs-Knorr procedure with AgOTf as a promoter and 2,4,6-tri-tert-butylpyridine as an acid scavenger. Reduction of the azide gave amine 21, which underwent acylation with $N$-Boc-amino acid 15. Global deprotection via hydrogenolysis and acid hydrolysis with an additional Zemplen de- $O$ benzoylation provided the fully deprotected 6-aminocaproic amide 22. Acylation with NHS ester 17 yielded lactose variant 5 (SQS-1-0-11-18). Notably, this high-yielding ( $\geq 80 \%$ per step) and streamlined synthetic route required only 16 total steps (13 steps LLS), compared to the previous 23 -step synthesis of lead compound 3 (SQS-1-0-5-18). ${ }^{13,14}$

Finally, synthesis of the regioisomeric 2-galactosamine variant $\mathbf{6}$ started with protected 2azidogalactosyl bromide $\mathbf{2 3}$, easily obtained on multi-gram scale in three steps from commercially available D-galactal ${ }^{18}$ (Scheme 3). Coupling of triterpene 13 with glycosyl bromide 23 under optimized phase transfer conditions $\left(\mathrm{K}_{2} \mathrm{CO}_{3}, \mathrm{Bu}_{4} \mathrm{NBr}\right.$, EtOAc, $\mathrm{H}_{2} \mathrm{O}, 45$ $\left.{ }^{\circ} \mathrm{C}\right)^{19}$ followed by careful deacetylation of the C6-hydroxyl gave the desired $\beta$-C28galactosyl ester $\mathbf{2 4}$. Glycosylation with disaccharide imidate $\mathbf{2 5}$ under TMSOTf catalysis at $-45^{\circ} \mathrm{C}$ then proceeded with a-selectivity, providing the desired triterpene-trisaccharide conjugate, whose azide group was reduced $(\mathrm{PhSeH})$ to give amine 26. Acylation with $\mathrm{N}$ Boc-amino acid 15, global deprotection to 6-aminocaproic amide 27, and final installation of the aryl iodide moiety as above provided 2-galactosamine variant $\mathbf{6}$ (SQS-1-0-12-18) in 19 total steps (13 steps LLS). ${ }^{14}$

In conclusion, we have demonstrated the efficient synthesis of a series of novel Quillaja saponin variants and developed a new, versatile synthetic route that provides modular, latestage access to diverse modifications in the linear oligosaccharide domain of this class. Notably, the original 23 -step route to the lead compound $\mathbf{3}$ was progressively shortened in dirhamnose variant 4 (22 steps), 2-galactosamine variant 6 (19 steps) and lactose variant 5 (16 steps). In addition, this divergent synthesis overcomes key limitations of our original convergent strategy, ${ }^{11,12,13}$ namely the demanding en bloc glycosylation of the triterpene with the entire trisaccharide donor, which was unsuccessful en route to lactose variant $\mathbf{5}$, and the need for pre-assembly of the entire trisaccharide moiety, which limits rapid exploration 
of different sugar residues in this domain. In contrast, this new divergent approach benefits from efficient glycosylations with simpler monosaccharide donors to provide versatile triterpene-monosaccharide intermediates for diversification with a variety of terminal disaccharides. Going forward, the efficiency and versatility of this divergent route will facilitate the rapid, streamlined preparation of a wide range of additional variants to identify novel saponin adjuvants with improved synthetic accessibility and scalability that will be necessary for future clinical advancement in vaccines.

\section{Supplementary Material}

Refer to Web version on PubMed Central for supplementary material.

\section{Acknowledgments}

This work is dedicated to the memory of our mentor and colleague, Prof. David Y. Gin (1967-2011). We thank J. S. Lewis, N. Pillarsetty, G. Ragupathi, and S. J. Danishefsky for helpful discussions, and G. Sukenick, H. Liu, H. Fang, and S. Rusli (MSKCC Analytical Core Facility) for expert mass spectral analyses. This research was supported by the European Commission (Marie Curie International Outgoing Fellowship to A.F.-T.), the U.S. NIH (R01 AI085622 to D.Y.G. and J. S. Lewis, R01 GM058833 to D.Y.G. and D.S.T., Cancer Center Support Grant P30 CA008748 to C. B. Thompson), William and Alice Goodwin and the Commonwealth Foundation for Cancer Research, and the Experimental Therapeutics Center of MSKCC.

\section{Notes and references}

1. (a) Moyle PM, Toth I. ChemMedChem. 2013; 8:360. [PubMed: 23316023] (b) Leroux-Roels G. Vaccine. 2010; 28:C25. [PubMed: 20713254]

2. Kensil CR, Patel U, Lennick M, Marciani D. J. Immunol. 1991; 146:431. [PubMed: 1987271]

3. Jacobsen NE, Fairbrother WJ, Kensil CR, Lim A, Wheeler DA, Powell MF. Carbohydr. Res. 1996; 280:1. [PubMed: 8581890]

4. Kim SK, Ragupathi G, Musselli C, Choi S-J, Park YS, Livingston PO. Vaccine. 1999; 18:597. [PubMed: 10547417]

5. (a) Van Braeckel E, Bourguignon P, Koutsoukos M, Clement F, Janssens M, Carletti I, Collard A, Demoitie M-A, Voss G, Leroux-Roels G, McNally L. Clin. Infect. Dis. 2011; 52:522. HIV. [PubMed: 21208909] (b) The RTS.S Clinical Trials Partnership. New Engl. J. Med. 2011; 365:1863. Malaria. [PubMed: 22007715] (c) Ragupathi G, Gardner JR, Livingston PO, Gin DY. Exp. Rev. Vaccines. 2011; 10:463. Cancer.

6. (a) Soltysik S, Bedore DA, Kensil CR. Ann. N. Y. Acad. Sci. 1993; 690:392. [PubMed: 8368766]

(b) Kamstrup S, San Martin R, Doberti A, Grande H, Daalsgard K. Vaccine. 2000; 18:2244.

[PubMed: 10717344]

7. Cleland JL, Kensil CR, Lim A, Jacobsen NE, Basa L, Spellman M, Wheeler DA, Wu J-Y, Powell MF. J. Pharm. Sci. 1996; 85:22. [PubMed: 8926578]

8. Pink JR, Kieny M-P. Vaccine. 2004; 22:2097. [PubMed: 15212010]

9. (a) Wang P, Kim Y-J, Navarro-Villalobos M, Rohde BD, Gin DY. J. Am. Chem. Soc. 2005; 127:3256. [PubMed: 15755124] (b) Kim Y-J, Wang P, Navarro-Villalobos M, Rohde BD, Derryberry J, Gin DY. J. Am. Chem. Soc. 2006; 128:11906. [PubMed: 16953631] (c) Deng K, Adams MM, Damani P, Livingston PO, Ragupathi G, Gin DY. Angew. Chem., Int. Ed. 2008; 47:6395.

10. Deng K, Adams MM, Gin DY. J. Am. Chem. Soc. 2008; 130:5860. [PubMed: 18410100]

11. Adams MM, Damani P, Perl N, Won A, Hong F, Livingston PO, Ragupathi G, Gin DY. J. Am. Chem. Soc. 2010; 132:1939. [PubMed: 20088518]

12. Chea EK, Fernández-Tejada A, Damani P, Adams MM, Gardner JR, Livingston PO, Ragupathi G, Gin DY. J. Am. Chem. Soc. 2012; 134:13448. [PubMed: 22866694] 
13. Fernández-Tejada A, Chea EK, George C, Pillarsetty N, Gardner JR, Livingston PO, Ragupathi G, Lewis JS, Tan DS, Gin DY. Nature Chem. 2014; 6:635. [PubMed: 24950335]

14. Step counts based on number of isolated, characterized intermediates

15. (a) Garcia BA, Poole JL, Gin DY. J. Am. Chem. Soc. 1997; 119:7597.(b) Garcia BA, Gin DY. J. Am. Chem. Soc. 2000; 122:4269.

16. Myers AG, Gin DY, Rogers DH. J. Am. Chem. Soc. 1994; 115:2036.

17. (a) Lichtenthaler FW, Kaji E, Weprek S. J. Org. Chem. 1985; 50:3505.(b) Kamath VP, Yeske RE, Gregson JM, Ratcliffe RM, Fang YR, Palcic MM. Carbohydr. Res. 2004; 339:1141. [PubMed: 15063203]

18. Leteux C, Veyrières A. J. Chem. Soc., Perkin Trans. 1. 1994:2647.

19. Zhu C, Tang P, Yu B. J. Am. Chem. Soc. 2008; 130:5872. [PubMed: 18407637] 


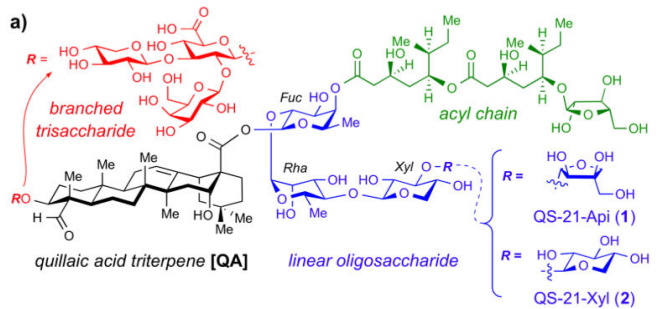

b)

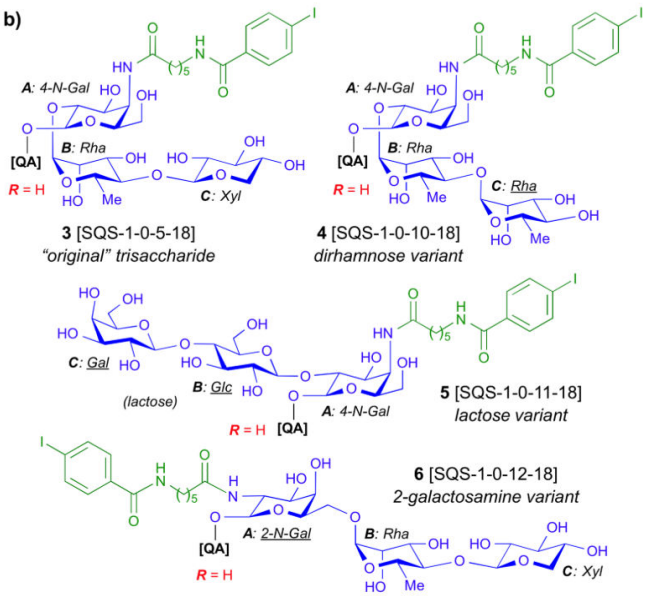

c) Previous convergent strategy

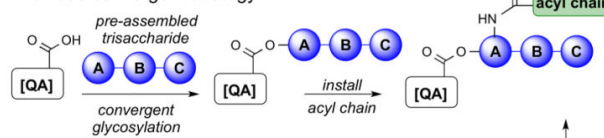

d) Divergent strategy in this work

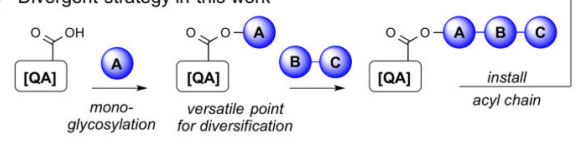

Fig. 1.

(a) Four structural domains of QS-21. (b) Structures of linear oligosaccharide domain variants 3-6. (c) Previous convergent strategy for synthesis of linear oligosaccharide variants 3 and 4. (d) New divergent strategy for synthesis of linear oligosaccharide variants 5 and 6. 


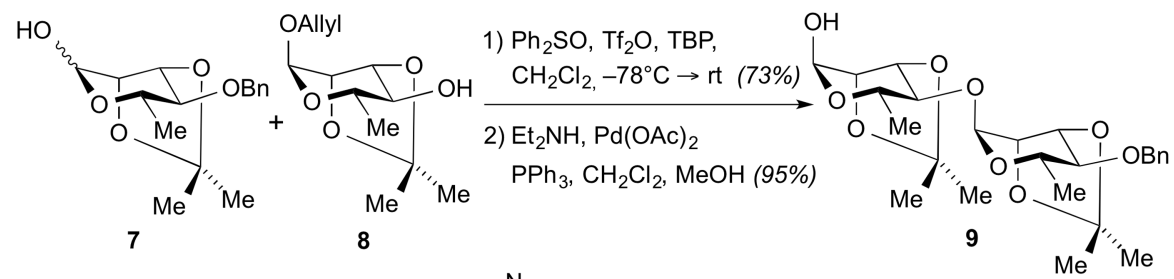

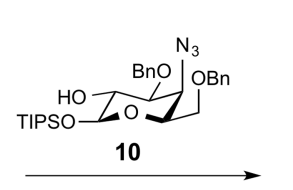

$\mathrm{Ph}_{2} \mathrm{SO}, \mathrm{Tf}_{2} \mathrm{O}, \mathrm{TBP}$ $\mathrm{CH}_{2} \mathrm{Cl}_{2},-78^{\circ} \mathrm{C} \rightarrow \mathrm{rt}$ (76\% brsm)

1) TBAF, $\mathrm{AcOH}, \mathrm{THF}$ $\mathrm{BnO} \mid \mathrm{OBn}$

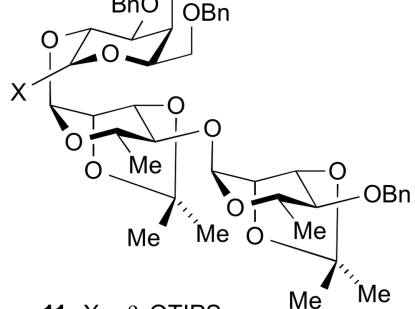

13, [PQA]-OH:

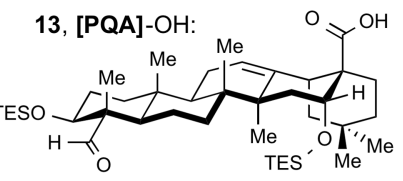

1) $\mathrm{BF}_{3} \mathrm{OEt}_{2}, 4 \AA \mathrm{MS}, \mathrm{CH}_{2} \mathrm{Cl}_{2}$ $-30{ }^{\circ} \mathrm{C}(73 \%)$

2) $\mathrm{PhSeH}, \mathrm{Et}_{3} \mathrm{~N}, 38^{\circ} \mathrm{C}(80 \%)$

2) $\mathrm{Cl}_{3} \mathrm{CCN}, \mathrm{DBU}, \mathrm{CH}_{2} \mathrm{Cl}_{2}\left(\begin{array}{l}11: \mathrm{X}=\alpha-\mathrm{O}=\alpha-\mathrm{OC}(\mathrm{NH}) \mathrm{CCl}_{3} \\ \text { 12: }\end{array}\right.$

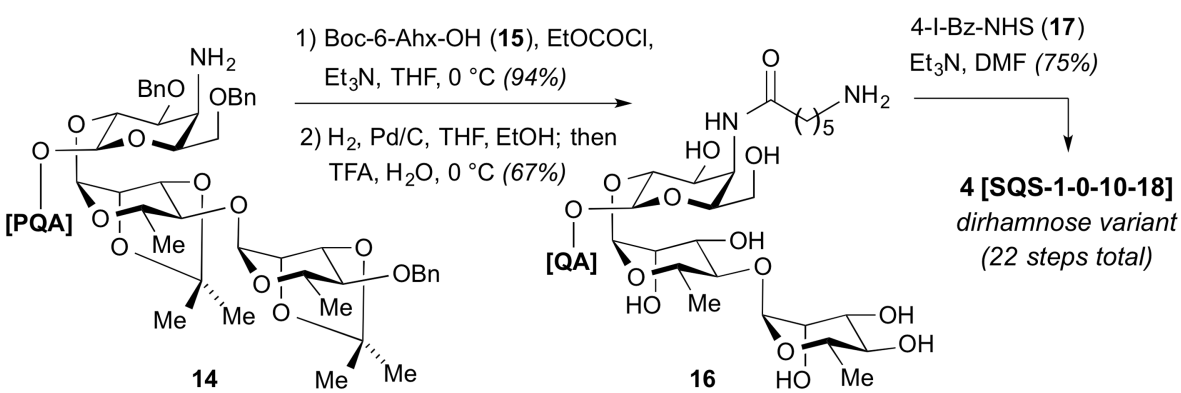

Scheme 1.

Synthesis of Dirhamnose Variant 4. Boc-6-Ahx-OH = N-Boc-6-aminohexanoic acid; brsm= based on recovered starting material; $\mathrm{MS}=$ molecular sieves; $\mathrm{NHS}=\mathrm{N}$ -

hydroxysuccinimide; PQA = protected quillaic acid (13); TBP = 2,4,6-tri-tert-butylpyridine. 

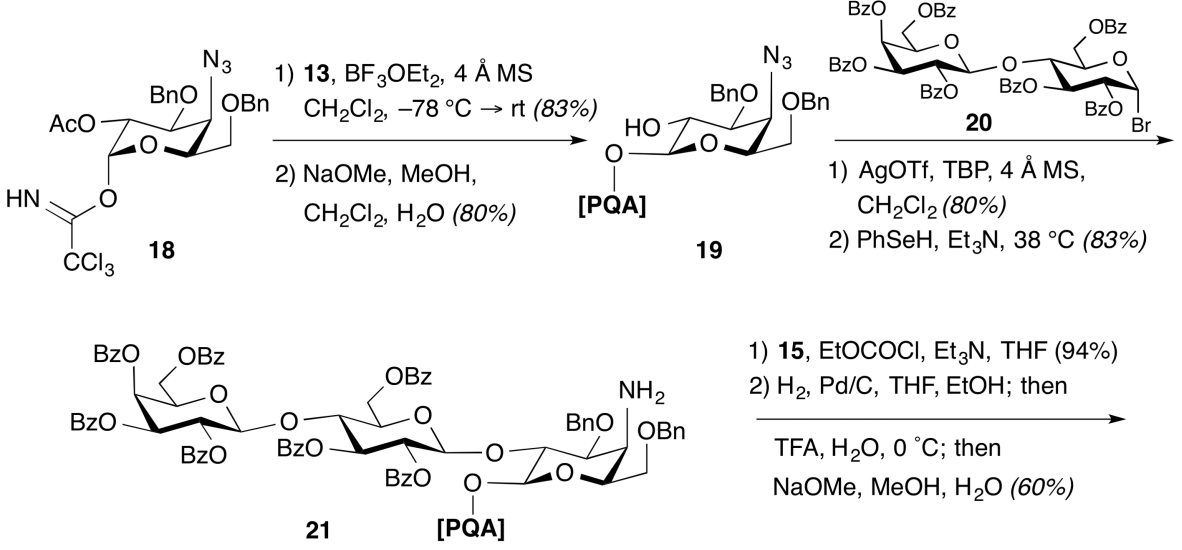

1) $15, \mathrm{EtOCOCl}, \mathrm{Et}_{3} \mathrm{~N}, \mathrm{THF}(94 \%)$

2) $\mathrm{H}_{2}, \mathrm{Pd} / \mathrm{C}, \mathrm{THF}, \mathrm{EtOH}$; then

TFA, $\mathrm{H}_{2} \mathrm{O}, 0^{\circ} \mathrm{C}$; then

$\mathrm{NaOMe}, \mathrm{MeOH}, \mathrm{H}_{2} \mathrm{O}(60 \%)$

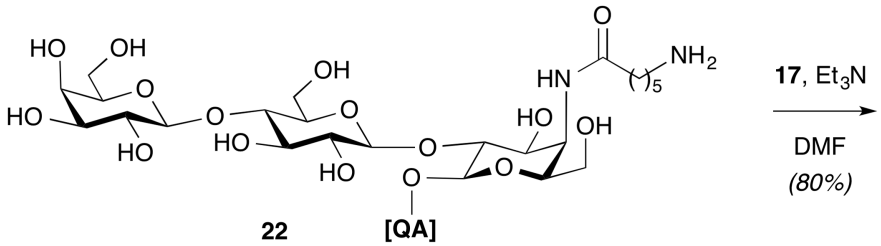

5 [SQS-1-0-11-18]

lactose variant

(16 steps total)

Scheme 2.

Synthesis of Lactose Variant 5. 

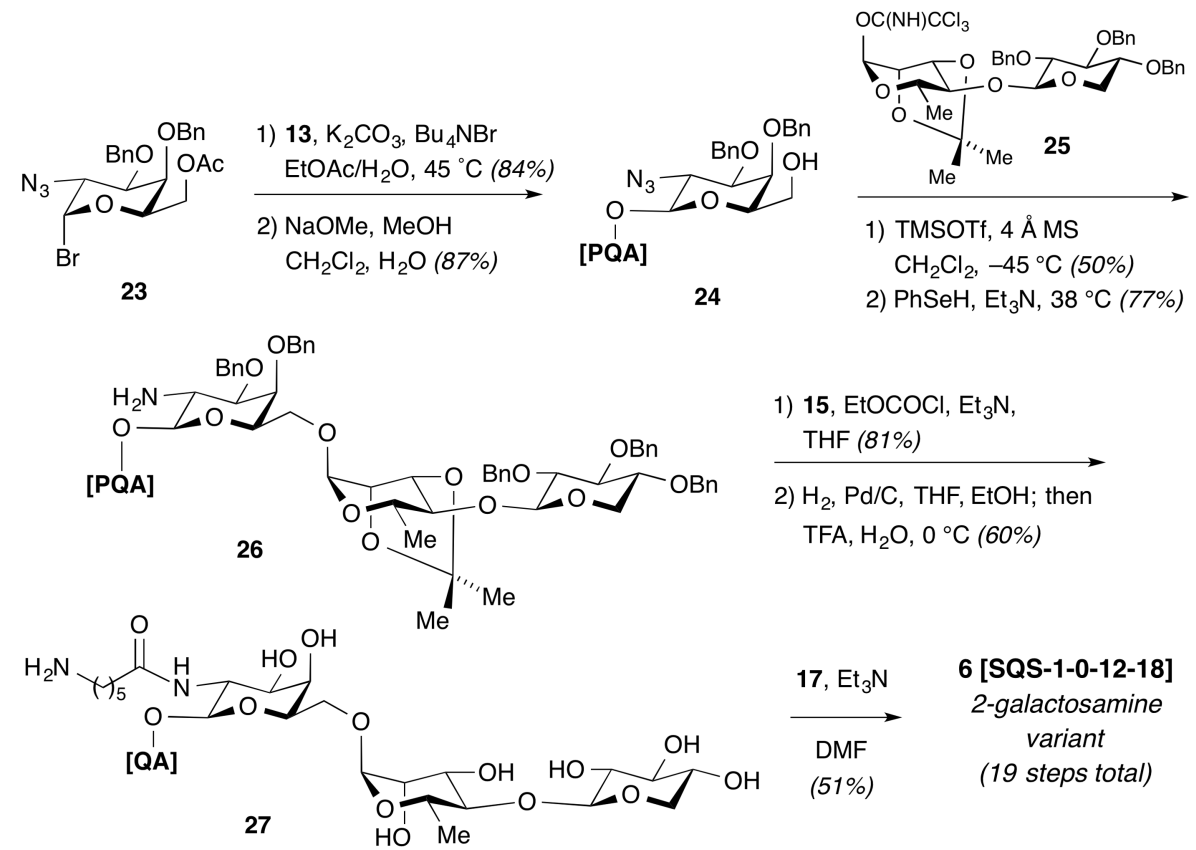

1) $15, \mathrm{EtOCOCl}, \mathrm{Et}_{3} \mathrm{~N}$ THF (81\%)

2) $\mathrm{H}_{2}, \mathrm{Pd} / \mathrm{C}, \mathrm{THF}, \mathrm{EtOH}$; then TFA, $\mathrm{H}_{2} \mathrm{O}, 0^{\circ} \mathrm{C}(60 \%)$

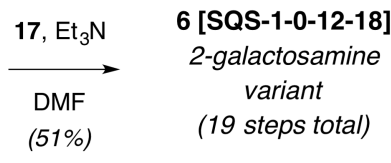

Scheme 3.

Synthesis of Regioisomeric 2-Galactosamine Variant 6. 